\title{
Do Better in Math: How Your Body Posture May Change Stereotype Threat Response
}

\author{
Erik Peper ${ }^{1 *}$, Richard Harvey ${ }^{1}$, Lauren Mason ${ }^{1}$, and I-Mei Lin ${ }^{2}$ \\ ${ }^{1}$ Institute for Holistic Health Studies/Department of Health Education, San Francisco State University, San Francisco, \\ California, USA \\ ${ }^{2}$ Department of Psychology, College of Humanities and Social Sciences, Kaohsiung Medical University, Kaohsiung, \\ Taiwan
}

\section{Abstract}

This study investigates posture on mental math performance. One hundred twenty-five students $(M=23.5$ years) participated as part of a class activity. Half of the students sat in an erect position while the other half sat in a slouched position and were asked to mentally subtract 7 serially from 964 for $30 \mathrm{~s}$. They then reversed the positions before repeating the math subtraction task beginning at 834 . They rated the math task difficulty on a scale from 0 (none) to 10 (extreme). The math test was rated significantly more difficult while sitting slouched $(M$ $=6.2)$ than while sitting erect $(M=4.9)$, ANOVA $[F(1,243)=17.06, p<.001]$. Participants with the highest test anxiety, math difficulty and blanking out scores (TAMDBOS) rated the math task significantly more difficult in the slouched position $(M=7.0)$ as compared to the erect position $(M=4.8)$, ANOVA $[F(1,75)=17.85, p<.001]$. Tor the participants with the lowest 30\% TAMDBOS, there was no significant difference between slouched $(M=4.90)$ and erect positions $(M=4.0)$. The participants with the highest TAMDBOS experienced significantly more somatic symptoms as compared with the lowest TAMDBOS. Discussed are processes such as stereotypic threat associated with a "defense reaction" by which posture can affect mental math and inhibit abstract thinking. Moreover, clinicians who work with students who have learning difficulty may improve outcome if they include posture changes.

Keywords: posture; math; depression; stereotype threat; empowerment; stress

Citation: Peper, E., Harvey, R., Mason, L., \& Lin, I.-M. (2018). Do better in math: How your body posture may change stereotype threat response. NeuroRegulation, 5(2), 67-74. http://dx.doi.org/10.15540/nr.5.2.67

*Address correspondence to: Erik Peper, $\mathrm{PhD}$, Institute for Holistic Healing Studies/Department of Health Education, San Francisco State University, 1600 Holloway Avenue, San Francisco, CA 94132, USA. Email: epeper@sfsu.edu

Copyright: () 2018. Peper et al. This is an Open Access article distributed under the terms of the Creative Commons Attribution License (CC-BY).

\author{
Edited by: \\ Rex L. Cannon, PhD, Knoxville Neurofeedback Group, Knoxville, \\ Tennessee, USA \\ Reviewed by: \\ Rex L. Cannon, PhD, Knoxville Neurofeedback Group, Knoxville, \\ Tennessee, USA \\ Randall Lyle, PhD, Mount Mercy University, Cedar Rapids, Iowa, \\ USA
}

\section{Introduction}

Many students perform poorly on cognitive tasks such as mental arithmetic when under situations of perceived threat (Moore, Vine, Wilson, \& Freeman, 2012; Schmader, Hall, \& Croft, 2015). Math anxiety generally refers to a set of reactions to perceived threats related to performance on math tasks. For example, the term stereotype threat refers to a type of performance decline applied when "...people underperform relative to their ability merely because they are aware of a negative stereotype about how they should perform-e.g., a female student aware of the stereotype that 'boys are better than girls at mathematics"' (Maloney, Schaeffer, \& Beilock, 2013, p. 116). When people are presented with a stereotype-based statement such as "extra pressure to succeed" as well as "threats to self-integrity and belonging," both result in anxiety reactions which reduce performing in math tasks (Spencer, Logel, \& Davies, 2016).

Ramirez, Shaw, and Maloney (2018, p. 9) offer their "Interpretation Account" (IA) framework for understanding math anxiety, that includes a list of sample interpretations of threat: 
- Existing cultural stereotypes (i.e., "Women hate math, so I must hate math as well"; Bieg, Goetz, Wolter, \& Hall, 2015).

- Societal beliefs around disfluent learning (i.e., "If you are having trouble learning something, then you are probably not going to perform very well"; Benjamin, Bjork, \& Schwartz, 1998; Koriat \& Bjork, 2006; Stigler \& Hiebert, 2004).

- Social interactions in the home ("My parents always help me with math homework because I am not very comfortable doing it on my own"; Maloney, Ramirez, Gunderson, Levine, \& Beilock, 2015).

- Social interactions in class ("My teacher gets really stressed out teaching math"; Beilock, Gunderson, Ramirez, \& Levine, 2010).

- Teaching pedagogy ("My teacher doesn't ask us questions or encourage us to think deeply about math because he/she believes that not everyone can be good at math"; Ramirez, Hooper, Kersting, Ferguson, \& Yeager, 2018).

- Lay beliefs about the meaning of heightened physiological arousal (i.e., "My heart is beating fast, I must be really nervous"; Jamieson, Nock, \& Mendes, 2012)."

Not only does the IA framework assist with distinguishing state-like and trait-like variations of math anxiety reactions, but it also provides a framework for identifying brain activity associated with math-anxiety reactions due to fact-based cognitions (e.g., I have not yet learned how to retrieve the answer to that math problem; however, I am capable of learning) versus stereotype-relevant cognitions (e.g., I am not expected to perform well because of a stereotype; Lamont, Swift, \& Abrams, 2015; Ramirez, Shaw, et al., 2018). Erickson (2015) points out that Danker and Anderson (2007) suggest cognitive models are able to distinguish between math retrieval and other representations in the parietal cortex and prefrontal cortex; however, "...Their surprising result was that both brain regions were active for each step but at differing levels of activation" (p. 23).

Other researchers have examined various kinds of brain activity associated with math anxiety due to negative evaluative self-talk interpretations or threat appraisals such as "I will never be motivated to learn math because I do not feel math is useful," which is focused on the amygdala, posterior parietal cortex (PPC), and dorsolateral prefrontal cortex (DLPFC). Young, Wu, and Menon (2012) used functional MRI (magnetic resonance imaging) with 7- to 9-year-old children to visualize brain activity while performing math tasks. Their brain scans revealed hyperactivity in the right amygdala region, responsible for processing negative emotions, and also found reduced activity in the PPC and DLPFC regions which are typically active during mathematical reasoning, and state: "These effects were specific to math anxiety and unrelated to general anxiety, intelligence, working memory, or reading ability" (Young, Wu, \& Menon, 2012, p. 492).

In contrast to negative evaluative self-talk (NEST) based on fact-based interpretations or threat appraisals of math performance, there are a variety of brain regions associated with persistent strain and stress under conditions of social-evaluative threat (SET). Whereas Ramirez, Shaw, et al. (2018) have provided types of interpretations or threat appraisals related to math performance, others such as Turner et al. (2002) suggest that math anxiety can result in toxic strain related to SET interpretations or appraisals when, for example, students perceive themselves as "vulnerable to public displays of incompetence" (p. 101). Similarly, Maloney et al. (2013), suggest that math performance may be interpreted as high stakes especially when the results are judged by those in power to decide whether they graduate or get a job in the future.

The consequences of SET based on interpretations or appraisals about math performance that are believed to be overwhelming and undermining are more profound than the consequences of NEST, based on interpretations or appraisals about math performance that are believed to be difficult yet manageable, with a bias towards a "growth mindset" (Boaler \& Dweck, 2016; Pohl, 2017). The consequences are not only regarding the decline in math performance itself but also in the effects of SET on health. Olff (1999) suggests that negative interpretations and appraisals of threat, whether related to math performance or any other topic, influence the immune system abilities to fight off disease.

Acute stress brought on by SET appraisals about a classroom math task (or almost any type of exam) can impair higher cortical functions by inhibiting working memory. Qin, Hermans, van Marle, Luo, and Fernández (2009) showed that "induced acute stress resulted in significantly reduced working memory-related activity in the dorsolateral prefrontal cortex and was accompanied by less deactivation in brain regions that are jointly referred to as the default mode network." Chronic stress, such as repeated threat perceptions associated with poor 
math performance, influences the medial prefrontal cortex, cause debranching and shrinkage of dendrites which is related to cognitive rigidity (McEwen et al., 2015). With declines in working memory as well as chronic shrinkage of dendrites comes impairment not only with math performance but with other cognitive processes as well (McEwen et al., 2015).

Developing strategies to reduce stress and regulate emotions allows students to optimize performance in many cognitive tasks (Arroyo et al., 2014). For example, students who have a positive self-concept of their mathematics ability perform better in math classes, possibly because they do not attribute poor math performance as a SET, but rather interpret failure as information and as an opportunity for learning and growth. As a method for training students to interpret poor math performance as feedback rather than as a SET, Shapiro, Williams, and Hambarchyan (2013) have proposed a MultiThreat Framework as a tool to illustrate how multiple personal and social influences impact girls' interest and performance in Science, Technology, Engineering, and Math (STEM) learning.

One aspect of the Multi-Threat Framework (Shapiro et al., 2013) includes raising awareness of physical body reactions to poor performance during STEM learning. For example, when students perform poorly on a math exam, they may slouch or collapse their posture, coincident with feelings of powerlessness, hopelessness, and defeat. The effect of expectancy related to future performance on STEM tasks or exams influences posture as well as other neuroendocrine responses. For example, if you feel that you are a "loser," not only might you slouch or collapse your posture, but testosterone levels may also continue to decrease (Smith \& Apicella, 2017) and cortisol levels may continue to increase.

In contrast, if a student feels like a "winner," they may hold their head high in an upright body posture. An upright body posture is associated with increased testosterone, decreased cortisol, greater confidence, mood, and strength when compared to a sustained slouched posture, which is associated with greater chronic neck, shoulder, and back pain as well as lower confidence and energy, depressive memory bias, and failure-related emotions (Briñol, Petty, \& Wagner, 2009; Canales, Cordás, Fiquer, Cavalcante, \& Moreno, 2010; Carney, Cuddy, \& Yap, 2010; Michalak, Mischnat, \& Teismann, 2014; Peper, Booiman, Lin, \& Harvey, 2016; Thrasher et al., 2011; Tsai, Peper, \& Lin, 2016; Wilson \& Peper, 2004).

Regardless of the source of negative thoughts associated with SET interpretations and stereotype threats, strategies for mitigating the effects of the negative thoughts include making physical body adjustments in posture. For example, when students change their posture during a 4-week posture feedback training period, they report significant improvements in physical functioning, energy levels, reduced fatigue, and health (Harvey, Mason, Peper, \& Joy, in press).

When individuals are hypervigilant or anticipating danger, their capacity for abstract thinking is inhibited in favor of mobilizing resources to respond immediately to a perceived physical threat (Sapolsky, 2015). There is a competitive relationship between posture (e.g., slouching versus sitting erect), cognitive performance (e.g., performance on a mental arithmetic task), and affect (e.g., emotions such as state-dependent anxiety and/or depression) as suggested by Brauer, Woollacott, and Shumway-Cook (2001). Others have suggested that positive thought processes are significantly easier to maintain in an upright, erect posture, while negative thoughts are more easily produced with a slouched, collapsed posture (Peper, Lin, Harvey, \& Perez, 2017; Tsai et al., 2016; Wilson \& Peper, 2004).

People tend to adapt a slouched posture while looking down at digital screens, watching various kinds of digital media on computer screens, or even sitting collapsed in a chair or couch during therapy. Our posture may impact the way we perceive ourselves, as well as the way others perceive us (Briñol et al., 2009). An upright posture tends to project an assertive, dominant, and powerful person; whereas sitting in a collapsed posture may project a submissive, defeated, or depressed individual. These postural cues about the status of an individual are processed nonverbally through neuroception of the observer (Porges, 2009, 2015; Porges \& Peper, 2015). Whereas many have examined the relationship between threat perceptions and math performance, the present study examined whether a postural intervention could mitigate poor performance on a simple math task. Therefore, the purpose of this study explores the extent to which adjustments in postural positions influence performance on a simple subtraction task under conditions of time pressure. 


\section{Method}

\section{Participants}

One hundred twenty-five college students (33 males, 78 females, 10 nonbinary), average age 23.5 years $(S D=5.9)$ participated in a regularly planned classroom demonstration investigating the relationship between posture (slouched or upright), mood, cognitive performance (performance on a simple math task), and symptom history. As a report about an effort to improve the quality of a classroom activity, this report of findings was exempted from Institutional Review Board oversight.

\section{Procedure}

While sitting in a class, students filled out a short, anonymous questionnaire, which asked them to rate their anxiety while taking exams, difficulty in performing math, blanking out while taking exams, depression, anxiety, and somatic symptoms on a scale from 1 to 10 . Two different sitting postures were clearly defined for participants: slouched/collapsed and erect/upright, as shown in Figure 1.

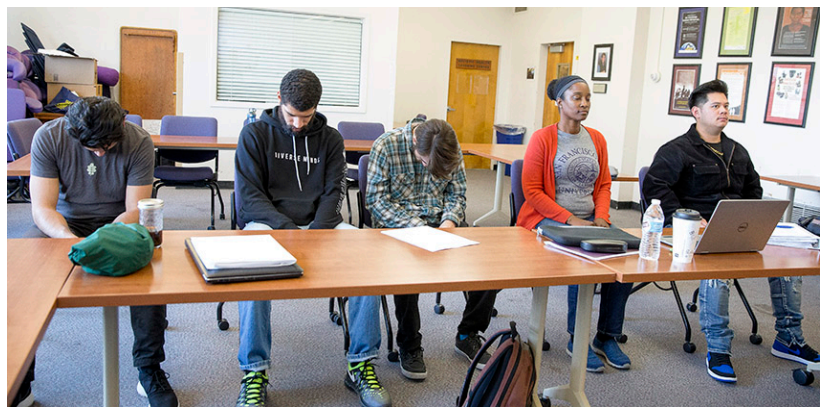

Figure 1. Sitting in a collapsed position and upright position. Photo from: http://news.sfsu.edu/newsstory/good-posture-important-physical-and-mental-health

To assume the collapsed position, they were asked to slouch and look down while slightly rounding the back. For the erect position, they were asked to sit upright with a slight arch in their back, while looking upward. After experiencing both postures, half of the students sat in the collapsed position while the other half sat in the upright position. While in this position, they were asked to rapidly subtract the number 7 from 843 sequentially for $15 \mathrm{~s}$. A counterbalancing scheme was used where they were then asked to switch positions. Those who were collapsed switched to sitting erect, and those who were erect switched to sitting collapsed. They were then to rapidly subtract the number 7 from 843 sequentially for $15 \mathrm{~s}$. Next, participants rated the difficulty in performing the mental math in each position, and in which position it was easier to perform the math.

\section{Results}

Among the participants, $56.4 \%$ reported that it was easier to perform math in the upright position, $16.1 \%$ in the collapsed position, and $27.4 \%$ reported position had no effect as shown in Figure 2.

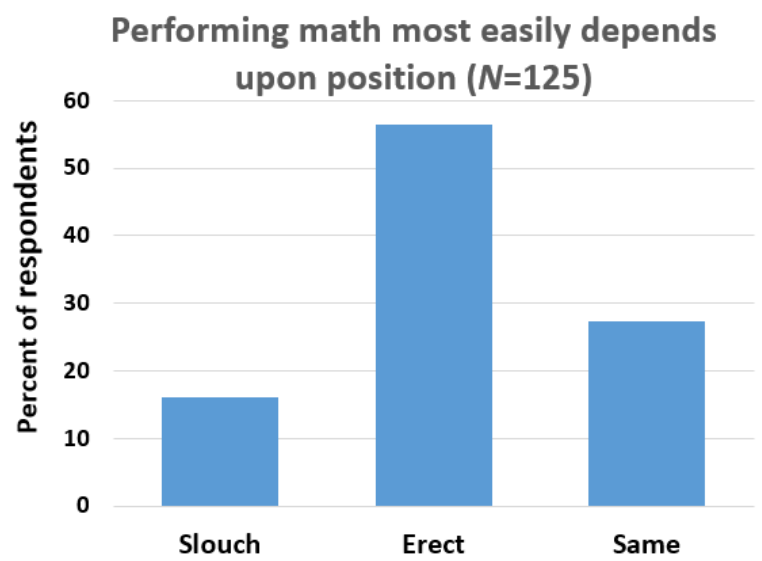

Figure 2. The percentage of participants who reported it was easier to perform the serial 7 math subtraction, by position.

It was significantly more difficult to perform the serial 7 subtractions in the collapsed position $(M=6.2 ; S D$ $=2.4)$ than in the erect position $(M=4.9 ; S D=2.5)$ ANOVA $[F(1,243)=17.06, p<.001]$ as shown in Figure 3.

\section{Math Difficulty and Position ( $N=125)$}

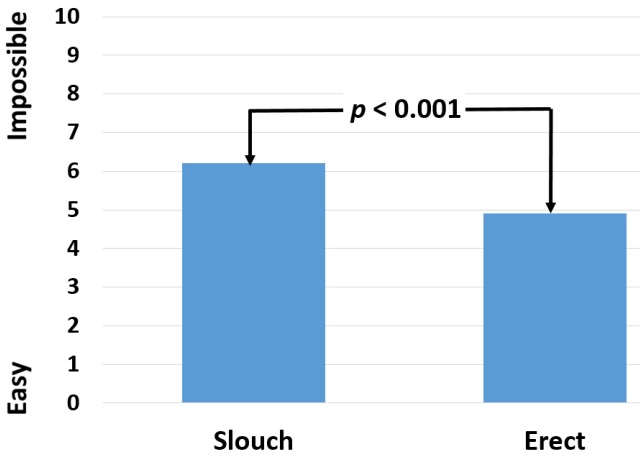

Figure 3. The relative subjective rating in the ease or difficulty of performing the serial 7 math subtraction in collapsed and upright positions. 
Effect of posture on math performance for the highest and lowest 30\% reporting test anxiety, math difficulty, and blanking out was statistically significant. They reported that the math task was significantly more difficult in the slouched position $(M$ $=7.0)$ as compared to the erect position $(M=4.8)$ ANOVA $[F(1,75)=17.85, p<.001]$. There was no significant difference for the participants with the lowest $30 \%$ of reported test anxiety, math difficulty, and blanking out between slouched $(M=4.9)$ and erect positions $(M=4.0)$. Also observed was a statistically significant difference in breathing difficulty $(p<.05)$, neck and shoulder tension $(p$ $<.05)$, headaches $(p<.01)$, anxiety $(p<.01)$, and sex (i.e., female) $(p<.01)$ for the group of participants with the highest test anxiety, math difficulty, and blanking out as compared with the lowest text anxiety levels (Figure 4).

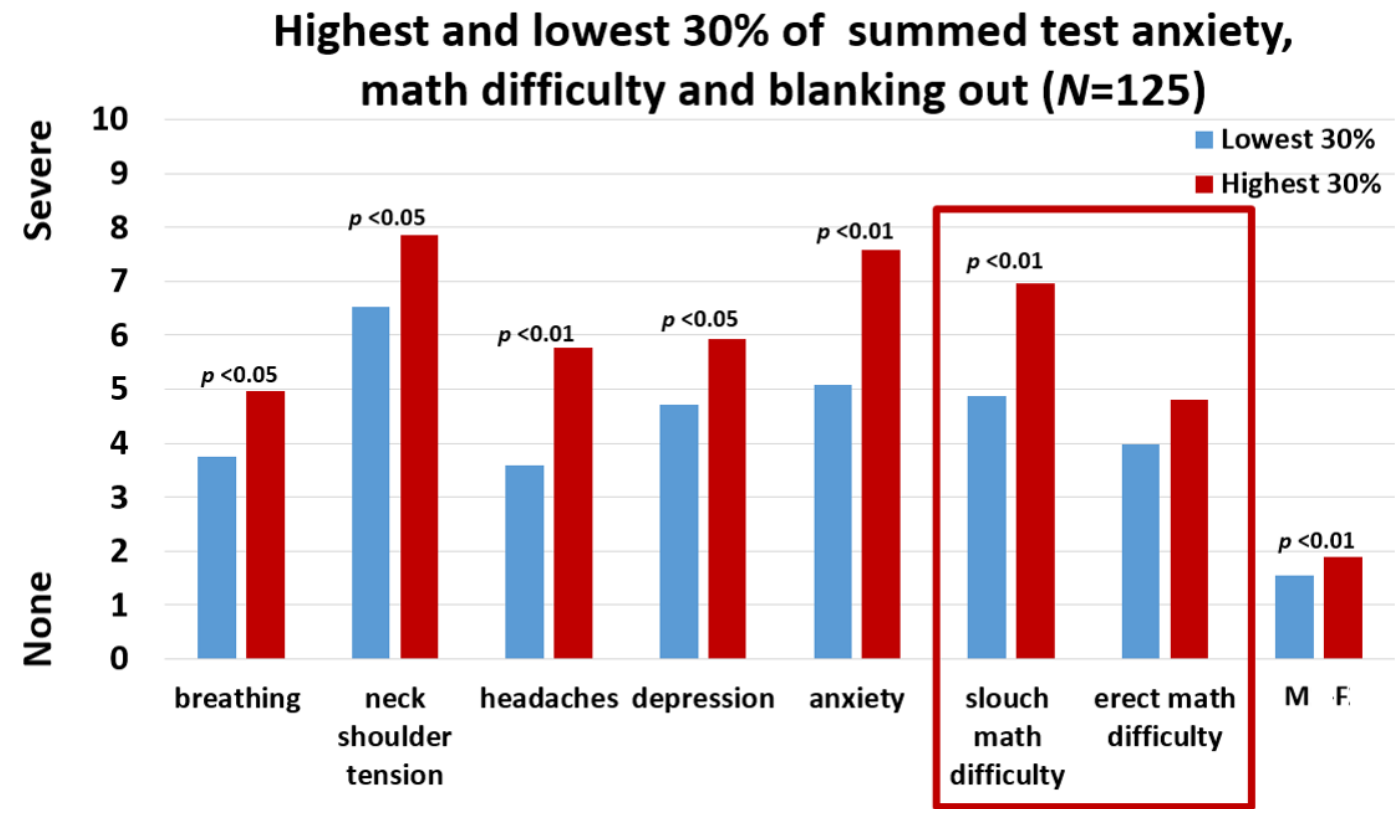

Figure 4. The highest and lowest $30 \%$ of summed test anxiety, math difficulty, and blanking out.

In comparing students with the highest versus lowest test anxiety, math difficulty, and blanking out, slouching positions significantly impacted math performance only for the high test anxiety, math difficulty, blanking out group; there was no significant difference when performing in the upright position (Figure 5).

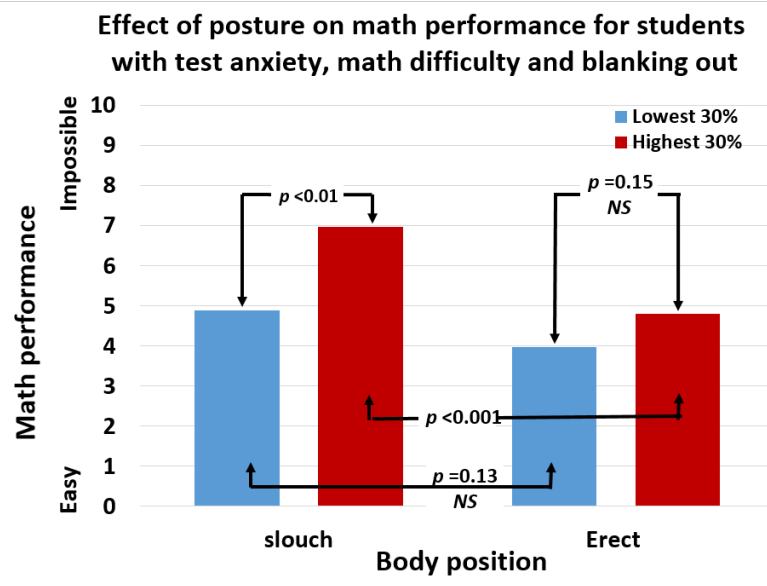

Figure 5. Effect of posture on math performance for students with test anxiety, math difficulty, and blanking out. 


\section{Discussion}

The slouched position was associated with increased difficulty in performing a math subtraction task for $15 \mathrm{~s}$, especially for students reporting higher test anxiety, math difficulty, and blanking out on exams. In contrast, slouched position had no significant effect on students who reported that they were not stressed about performance.

Self-reported anxiety levels have been correlated with a significant increase in breathing difficulty, neck and shoulder tension, headaches, depression, and anxiety, which confirmed the previous findings that students with higher math anxiety have increased physiological activation such as neural activation, heart rate, and increased cortisol (Faust, 1992; Lyons \& Beilock, 2012; Pletzer, Kronbichler, Nuerk, \& Kerschbaum, 2015). Most likely, the students attribute physiological reactions such as increased heart rate and breathing changes negatively, which amplifies their negative selfperception and exacerbates their anxiety symptoms; this may then inhibit their cognitive ability to perform on math tasks.

The activation of a "defense reaction," as well as curling into a slouching posture (flexor response), is probably a classically conditioned process since most people trigger the defense pattern under conditions of perceived physical threat. The activation of this defense pattern, and corresponding decrease in the performance of mental math, is associated with reduced levels of abstract thinking and frontal cortical deactivation. This biological defense response is triggered if the person expects the situation to be dangerous when there are conditions of SET among those who self-report that they have test anxiety, math difficulty, and blanking out on exams. Changing posture from a collapsed/slouched position to an erect/upright posture appears to inhibit the defense reaction; thus, the person may perform better on the math task (serial-7 subtraction under time pressure for $15 \mathrm{~s}$ ).

Head-upright/erect postures may make it easier to access positive and empowering thoughts and memories, thereby helping students to perform better. This expanded upright position is an indicator of feeling safe and empowered. This upright posture inhibits the defense reaction and increases feelings of safety, which relate to the findings that the head-upright, erect posture or position make it easier to access positive and empowering thoughts and memories (Peper et al., 2017).
The significant effect of the upright posture may have occurred because the task was very neutral and the students did the task without anticipating the feeling of defeat or hopelessness. If a student already felt defeated and "knew" that they could not perform, the erect posture may have less benefit. In those cases, the student would also need to transform their cognition and change their underlying beliefs. Changing beliefs and self-talk may be slightly easier to perform when the person simultaneously changes their body postures to an erect position; since thoughts and feelings are connected, and in the erect position it is easier to access positive thoughts.

The research findings suggest that students, especially those who are anxious or fearful of math and blanking out during exams, could benefit from sitting upright instead of slouched while studying and taking exams to optimize performance and have greater access to positive thoughts and memories.

\section{Implications for neurofeed back and therapy}

Many therapists work with clients who have learning disabilities and use neurofeedback as the primary intervention. This research suggests that therapists need to be aware that posture impacts performance, especially with clients who feel judged, threatened, and/or have low self-esteem. Similarly, many students seek tutoring or counseling, and those who simultaneously report somatic symptoms associated with anxiety may especially benefit from incorporating posture awareness and retraining in addition to any learning strategies designed to improve study habits.

The findings of this study suggest that if participants have test anxiety, fear of math, report blanking out on exams, and appear in a slouched posture, the first interventions should include strategies not only to reduce anxiety and increase cognitive reframing but also to improve posture. By changing body posture, the classically conditioned response to have a defense reaction to perceived threats is interrupted. Classroom learning processes are optimized when learners feel safe.

For highly anxious participants who also slouch habitually, posture awareness and retraining can be learned with posture feedback devices such as an UpRight. We recommend that the participant uses posture feedback to become aware of the situations that are associated with slouching, such as ergonomic factors (looking down at the screen), being tired, and having depressive thoughts or 
feeling powerless and defeated. The moment participants experience posture feedback, they have the option to shift to an upright posture and perform interventions to counter the factors that caused the slouching. These include ergonomic changes of their computer or laptop, transforming self-critical thoughts to empowering thoughts, and taking a break or doing exercise when tired. When students practice these interventions for 4 weeks, they report an increase of confidence, decrease in stress levels, and an improvement in health and performance (Harvey et al., in press). Equally important is to teach the participants somatic self-regulation strategies to reduce somatic complaints. These may include slower breathing, heart rate variability training, and muscle relaxation. The training needs to be generalized and taught how to do this at home, school, or work.

We recommend that therapists observe and help clients to optimize their posture in the office and at home. By guiding clients through two different positions as described in the article, the client may subjectively experience that one type of posture appears to inhibit cognitive performance while the other posture increases performance. This approach often increases motivation because the participant can now make choices based upon selfexperience.

The take home message echoes what your mother said, "Don't slouch. Sit up straight!"

- If you feel secure and safe, posture has little to no effect on performance: you can be collapsed or slouched.

- If you are anxious and fearful, sitting erect may improve your performance.

- If you want to become aware when you slouch, posture feedback from a wearable posture feedback device such as an UpRight can provide tactile feedback each time you slouch; then you can implement strategies to sit erect.

- If you automatically slouch while working at the computer or sitting in chair, change your furniture so that you sit in an upright position while studying or watching digital devices.

- If you experience significant somatic symptoms such as headaches, breathing difficulty, neck and shoulder tension, or depression and anxiety, learn self-regulation skills, such as slower diaphragmatic breathing and heartrate variability training in conjunction with changing negative self-talk to positive self-talk to positively impact performance and personal experience.

\section{References}

Arroyo, I., Woolf, B. P., Burelson, W., Muldner, K., Rai, D., \& Tai, M. (2014). A multimedia adaptive tutoring system for mathematics that addresses cognition, metacognition and affect. International Journal of Artificial Intelligence in Education, 24(4), 387-426. http://dx.doi.org/10.1007/s40593014-0023-y

Beilock, S. L., Gunderson, E. A., Ramirez, G., \& Levine, S. C. (2010). Female teachers' math anxiety affects girls' math achievement. Proceedings of the National Academy of Sciences of the United States of America, 107(5), 18601863. http://dx.doi.org/10.1073/pnas.0910967107

Benjamin, A. S., Bjork, R. A., \& Schwartz, B. L. (1998). The mismeasure of memory: When retrieval fluency is misleading as a metamnemonic index. Journal of Experimental Psychology: General, 127(1), 55-68. http://dx.doi.org/ 10.1037/0096-3445.127.1.55

Bieg, M., Goetz, T., Wolter, I., \& Hall, N. C. (2015). Gender stereotype endorsement differentially predicts girls' and boys' trait-state discrepancy in math anxiety. Frontiers in Psycholology, 6, 1404. http://dx.doi.org/10.3389 /fpsyg.2015.01404

Boaler, J., \& Dweck, C. (2016). Mathematical mindsets: Unleashing students' potential through creative math, inspiring messages, and innovative teaching. San Francisco, CA: Jossey-Bass.

Brauer, S. G., Woollacott, M., \& Shumway-Cook, A. (2001). The interacting effects of cognitive demand and recovery of postural stability in balance-impaired elderly persons. The Journals of Gerontology Series A, 56(8), M489-M496. http://dx.doi.org/10.1093/gerona/56.8.M489

Briñol, P., Petty, R. E., \& Wagner, B. (2009). Body posture effects on self-evaluation: A self-validation approach. European Journal of Social Psychology, 39(6), 1053-1064. http://dx.doi.org/10.1002/ejsp.607

Canales, J. Z., Cordás, T. A., Fiquer, J. T., Cavalcante, A. F., \& Moreno, R. A. (2010). Posture and body image in individuals with major depressive disorder: A controlled study. Revista Brasileira de Psiquiatria, 32(4), 375-380. http://dx.doi.org /10.1590/S1516-44462010000400010

Carney, D. R., Cuddy, A. J. C., \& Yap, A. J. (2010). Power posing: Brief nonverbal displays affect neuroendocrine levels and risk tolerance. Psychological Science, 21(10), 1363-1368. http://dx.doi.org/10.1177/0956797610383437

Danker, J. F., \& Anderson, J. R. (2007). The roles of prefrontal and posterior parietal cortex in algebra problem solving: A case of using cognitive modeling to inform neuroimaging data. Neurolmage, 35(3), 1365-1377. http://dx.doi.org /10.1016/j.neuroimage.2007.01.032

Erickson, S. L. (2015). Math Anxiety and Metacognition in Mathematics Education (Unpublished doctoral dissertation). University of California, Merced.

Faust, M. W. (1992). Analysis of physiological reactivity in mathematics anxiety (Unpublished doctoral dissertation). Bowling Green State University, Bowling Green, $\mathrm{OH}$.

Harvey, R., Mason, L., Peper, E., \& Joy, M. (in press). Effect of Posture Feedback Training on Health. Applied Psychophysiology and Biofeedback.

Jamieson, J. P., Nock, M. K., \& Mendes, W. B. (2012). Mind over matter: Reappraising arousal improves cardiovascular and cognitive responses to stress. Journal of Experimental Psychology: General, 141(3), 417-422. http://dx.doi.org/10.1037/a0025719

Koriat, A., \& Bjork, R. A. (2006). Mending metacognitive illusions: A comparison of mnemonic-based and theory-based 
procedures. Journal of Experimental Psychology: Learning, Memory, and Cognition, 32(5),1133-1145. http://dx.doi.org/ 10.1037/0278-7393.32.5.1133

Lamont, R. A., Swift, H. J., \& Abrams, D. (2015). A review and meta-analysis of age-based stereotype threat: Negative stereotypes, not facts, do the damage. Psychology and Aging, 30(1), 180-193. http://dx.doi.org/10.1037/a0038586

Lyons, I. M., \& Beilock, S. L. (2012). When math hurts: Math anxiety predicts pain network activation in anticipation of doing math. PLoS ONE, 7(10), e48076. http://dx.doi.org/10.1371/journal.pone.0048076

Maloney, E. A., Ramirez, G., Gunderson, E. A., Levine, S. C., \& Beilock, S. L. (2015). Intergenerational Effects of Parents' Math Anxiety on Children's Math Achievement and Anxiety. Psychological Science, 26(9), 1480-1488. http://dx.doi.org $/ 10.1177 / 0956797615592630$

Maloney, E. A., Schaeffer, M. W., \& Beilock, S. L. (2013). Mathematics anxiety and stereotype threat: Shared mechanisms, negative consequences and promising interventions. Research in Mathematics Education, 15(2), 115-128. http://dx.doi.org/10.1080/14794802.2013.797744

McEwen, B. S., Bowles, N. P., Gray, J. D., Hill, M. N., Hunter, R. G., Karatsoreos, I. N., \& Nasca, C. (2015). Mechanisms of stress in the brain. Nature Neuroscience, 18(10), 1353-1363. http://dx.doi.org/10.1038/nn.4086

Michalak, J., Mischnat, J., \& Teismann, T. (2014). Sitting posture makes a difference-Embodiment effects on depressive memory bias. Clinical Psychology \& Psychotherapy, 21(6), 519-524. http://dx.doi.org/10.1002/cpp.1890

Moore, L. J., Vine, S. J., Wilson, M. R., \& Freeman, P. (2012). The effect of challenge and threat states on performance: An examination of potential mechanisms. Psychophysiology, 49(10), 1417-1425. http://dx.doi.org/10.1111/j.14698986.2012.01449.x

Olff, M. (1999). Stress, depression and immunity: The role of defense and coping styles. Psychiatry Research, 85(1), 7-15. http://dx.doi.org/10.1016/S0165-1781(98)00139-5

Peper, E., Booiman, A., Lin, I.-M., \& Harvey, R. (2016). Increase strength and mood with posture. Biofeedback, 44(2), 66-72. http://dx.doi.org/10.5298/1081-5937-44.2.04

Peper, E., Lin, I.-M., Harvey, R., \& Perez, J. (2017). How posture affects memory recall and mood. Biofeedback, 45(2), 36-41. http://dx.doi.org/10.5298/1081-5937-45.2.01

Pletzer, B., Kronbichler, M., Nuerk, H.-C., \& Kerschbaum, H. H. (2015). Mathematics anxiety reduces default mode network deactivation in response to numerical tasks. Frontiers in Human Neuroscience, 9, 202. http://dx.doi.org/10.3389 Ifnhum.2015.00202

Pohl, K. A. (2017). "I'm just not good at math!" Rethinking what you know about mathematics. Learning to Teach, 5(1). Retrieved from http://utdr.utoledo.edu/learningtoteach /vol5/iss $1 / 5$

Porges, S. W. (2009). The polyvagal theory: New insights into adaptive reactions of the autonomic nervous system. Cleveland Clinic Journal of Medicine, 76(Suppl. 2), S86-S90. http://dx.doi.org/10.3949/ccjm.76.s2.17

Porges, S. W. (2015). Making the world safe for our children: Down-regulating defence and up-regulating social engagement to 'optimise' the human experience. Children Australia, 40(2), 114-123. https://dx.doi.org/10.1017 /cha.2015.12

Porges, S. W., \& Peper, E. (2015). When not saying NO does not mean Yes: Psychophysiological factors involved in date rape. Biofeedback, 43(1), 45-48. http://dx.doi.org/10.5298/10815937-43.1.01
Qin, S., Hermans, E. J., van Marle, H. J. F., Luo, J., \& Fernandez, G. (2009). Acute psychological stress reduces working memory-related activity in the dorsolateral prefrontal cortex. Biological Psychiatry, 66(1), 25-32. http://dx.doi.org/10.1016/j.biopsych.2009.03.006

Ramirez, G., Hooper, S. Y., Kersting, N. B., Ferguson, R., \& Yeager, D. (2018). Teacher Math Anxiety Relates to Adolescent Students' Math Achievement. AERA Open, 4(1). http://dx.doi.org/10.1177/2332858418756052

Ramirez, G., Shaw, S. T., \& Maloney, E. A. (2018). Math anxiety: Past research, promising interventions, and a new interpretation framework. Educational Psychologist, online. http://dx.doi.org/10.1080/00461520.2018.1447384

Sapolsky, R. M. (2015). Stress and the brain: Individual variability and the inverted-U. Nature Neuroscience, 18(10), 13441346. http://dx.doi.org/10.1038/nn.4109

Schmader, T., Hall, W., \& Croft, A. (2015). Stereotype threat in intergroup relations. In M. Mikulincer, P. R. Shaver, J. F. Dovidio, \& J. A. Simpson (Eds.), APA handbooks in psychology. APA Handbook of Personality and Social Psychology, Vol. 2. Group processes (pp. 447-471). Washington, DC: American Psychological Association. http://dx.doi.org/10.1037/14342-017

Shapiro, J. R., Williams, A. M., \& Hambarchyan, M. (2013). Are all interventions created equal? A multi-threat approach to tailoring stereotype threat interventions. Journal of Personality and Social Psychology, 104(2), 277-288. http://dx.doi.org/10.1037/a0030461

Smith, K. M., \& Apicella, C. L. (2017). Winners, losers, and posers: The effect of power poses on testosterone and risktaking following competition. Hormones and Behavior, 92, 172-181. http://dx.doi.org/10.1016/j.yhbeh.2016.11.003

Spencer, S. J., Logel, C., \& Davies, P. G. (2016). Stereotype threat. Annual Review of Psychology, 67, 415-437. http://dx.doi.org/10.1146/annurev-psych-073115-103235

Stigler, J. W., \& Hiebert, J. (2004). Improving mathematics teaching. Educational Leadership, 61(5), 12-17.

Thrasher, M., Van der Zwaag, M. D., Bianchi-Berthouze, N., \& Westerink, J. H. D. (2011). Mood Recognition based on upper body posture and movement features. Affective Computing and Intelligent Interaction, 377-386.

Tsai, H.-Y., Peper, E., \& Lin, I.-M. (2016). EEG patterns under positive/negative body postures and emotion recall tasks. NeuroRegulation, 3(1), 23-27. http://dx.doi.org/10.15540 Inr.3.1.23

Turner, J. C., Midgley, C., Meyer, D. K., Ghenn, M., Anderman, E. M., Kang, Y., \& Patrick, H. (2002). The classroom environment and students' reports of avoidance strategies in mathematics: A multimethod study. Journal of Educational Psychology, 94(1), 88-106. http://dx.doi.org/10.1037/00220663.94.1.88

Wilson, V. E., \& Peper, E. (2004). The effects of upright and slumped postures on the recall of positive and negative thoughts. Applied Psychophysiology and Biofeedback, 29(3), 189-195. /B:APBI.0000039057.32963.34

Young, C. B., Wu, S. S., \& Menon, V. (2012). The neurodevelopmental basis of math anxiety. Psychological Science, 23(5), 492-501. http://dx.doi.org/10.1177 /0956797611429134

Received: May 11, 2018

Accepted: May 15, 2018

Published: June 30, 2018 